\title{
An Easy and Efficient Protocol for the Synthesis of 2,3-Dihydroquinazolinones Using a Low Cost and Reusable Heterogeneous Catalyst
}

\author{
Bashir A. Dar ${ }^{1, *}$, Akshya K. Sahu ${ }^{1}$, Praveen Patidar ${ }^{1}$, jyoti patial ${ }^{1}$, Parveen Sharma ${ }^{1}$, Meena Sharma ${ }^{2}$, \\ Baldev Singh ${ }^{1}$
}

${ }^{1}$ NPC \& Catalysis, Indian Institute of Integrative Medicine (CSIR), Canal Road Jammu 180001,(J \& K) India

${ }^{2}$ Department of Chemistry University of Jammu. (J \& K) 180004, India

\begin{abstract}
Clays revealed high catalytic activity for the synthesis of a series of substituted 2, 3-dihydro-2-phenylquinazolin-4(1H)-one. The synthes is was carried out by reacting Anthranilamide and various substituted aldehydes in acetonitrile at room temperature in the presence of a small amount of the catalyst. Several solvents were examined for this reaction; however, in terms of reaction yield and time, Acetonitrile was found to be the optimum solvent.
\end{abstract}

Keywords Condensation, Cyclization, Heterogeneous Catalysis, Clay

\section{Introduction}

The evolution of simple and efficient synthetic routes to organic compounds from readily available and proficient reagents is one of the foremost challenges in organic synthesis. The field of heterogeneous catalysis has captivated the interest of researchers working in the field of catalysis due to increasing necessity for more environmentally acceptable processes in the chemical industry focusing largely on chemical yield, eliminating waste at source and circumventing the use of perilous materials (1). In this sense, clay catalyzed organic reactions have many advantages, such as ease of handling, separation, recycling, environmentally safe disposal, easy availability and their low cost. In addition to that clay minerals occur abundantly in nature and their high surface area, sorptive and ion-exchange properties have been exploited for catalytic applications through decades. Therefore, clay as a substitute of homogeneous catalyst or an expensive heterogeneous catalyst seems highly desirable (2).

2,3-Dihydroquinazo linones are the group of heterocyclic compounds in which different substitutions can be made to show pharmacological, Biological and Medicinal activity e.g. Antitumor, Antibiotic, Antipyretic, analgesic, antihypertensive, diuretic, Antihistaminic, antidepressant, and vasodilating agent(3). In addition 2,3dihydro-2-phenylquinazolin- $4(1 \mathrm{H})$-ones are potent

* Corresponding author:

bashir15 dar@yahoo.com (Bashir A. Dar)

Published online at http://journal.sapub.org/chemistry

Copyright (C) 2012 Scientific \& Academic Publishing. All Rights Reserved tubulin inhibitors with impressive antiprolivative activity against several human cancers with $\mathrm{IC}_{50}$ value in nano molar concentration. It acts analogously to Colchicine (inhibitors of tubulin poly merization) by binding to $\alpha, \beta$ - tublin (4). The 2,3-disubstituted quinazolones have been predicted to possess antiviral and antihypertensive activities (5). Additionally, these compounds can easily be oxidized to their quinazolin-4(3H)-one analogs, which is defined as a class of molecules that are capable of binding to multiple receptors with high affinity (6). These compounds also prove prospective antiprotozoal, immunosuppressive, and anticancer activities, the latter of which have been studied most frequently.

Various synthetic methods have been reported to prepare this class of compound using an assortment of catalysts like Iodine in Ionic Liquids (7), tetra butyl ammonium bromide(8), iridium (9), ionic liquids (10), iodine (11), ammonium chloride (12), [b mim] HSO4 (13), gallium trifluoro methane sulfonate (14), some Bronsted acids (15), $\mathrm{TiCl} / \mathrm{Zn}$ (16), phosphoric acid (17), citric acid (18), copper chloride (19) and some other catalytic systems like low valent titanium (20) etc. Su W has reported a method for synthesis by reductive cyclisation of o-nitrobenzamide or o-azidobenzamide with aldehydes and ketones promoted by metallic samarium and a catalytic amount of iodine or $\mathrm{SmI}_{2}$ (21). Due to some drawbacks of these procedures such as tedious process, long reaction times, harsh reaction conditions, poor yields along with the use of non-recyclable and toxic catalysts sometimes ineffectiveness associated with most of these catalysts demands development of some greener process involving low cost, easily available, easy to handle and efficient catalysts. We have developed an 
environmentally benign, high yielding and kinetically fast synthesis of 2, 3-dihydro-2-phenylquinazolin-4(1H)-one by using Anthranilamide with different substituted benzaldehyde by using clay catalyst. It is inexpensive, non-hazardous, recyclable, efficient and easy to separate fro $m$ the reaction mixture $v$ ia simp le filtration (22). We tried different clays, out of which Montmorilonite KSF shows better activity in terms of high yield with no side products and could be recycled at least six times and the desired product can be isolated in excellent yield in each run .<smiles>NC(=O)c1ccccc1N</smiles>

Scheme 1.

\section{Experimentalx}

\subsection{Gener al Procedure}

Various substituted aldehyde (1 equiv), anthranilamide (1 equiv), catalyst ( 0.1 equiv) was stirred at room temperature in acetonitrile for a specified period of time. After the completition of the reaction, monitered by the TLC, the catalyst was filtered and washed with ethyl acetate and the resulting filterate was dried and concentrated on rotavapour. The product was purified by crystallization technique using Ethyl acetate and Hexane as two solvent to afford the pure 2, 3-dihydroquinazo lin-4(1H)-one. The products thus obtained are characterized by HRMS, NMR. The spectral data were found to be consistent with authentic samples.

\section{Result and Discussion}

At the onset of the research, we investigated the model cyclo-condensation reaction between anthranilamdes and 4-chlorobenzaldehyde (Scheme.1) at room temperature and under different reaction media. After screening a variety of reaction media, Acetonitrile was found to be the most effective medium for the generation of the desired product (Table 1, entry 1) with no side products which may be due to the dipole mo ment (3.92 D) of Acetonitrile. The use of other solvents such as DCM and methanol (Table 1, entry 2and 3) was examined which did not improve the product yield but produce some unidentified by-products. When the reactions were conducted in water, the expected products were obtained in lower yields and with longer reaction times compared to organic solvents used, but still it was better than those earlier reports. (Table 1, entry 6). The lower yield obtained in water medium may be due to the suppression of condensation, following Le-Chatliers principle.
Table 1. The reaction of la and $2 \mathrm{a}$ in the presence of Clay supported Heteropolyacids under various conditions

\begin{tabular}{|c|c|c|c|}
\hline Entry & Solvent & Time(min) & Yield $^{\mathrm{b}}(\%)$ \\
\hline 1 & Acetonitrile & 10 & 99 \\
\hline 2 & DCM & 15 & 96 \\
\hline 3 & Methanol & 30 & 94 \\
\hline 4 & n-butanol & 20 & 92 \\
\hline 5 & Toluene & 30 & 85 \\
\hline 6 & Chloroform & 30 & 93 \\
\hline 7 & Water & 45 & 84 \\
\hline
\end{tabular}

${ }^{\mathrm{a}}$ Reaction conditions: all the reactions were carried out using 2-aminobenzamide $1 \mathrm{a}(1.0 \mathrm{mmol})$, aldehyde $2 \mathrm{a}(1.0 \mathrm{mmol})$ and Catalyst $(10 \%, w / w)$ at room temperature.

${ }^{\mathrm{b}}$ Isolated yield.

To show the merit of the present work we further compared the as prepared catalysts with those reported in the literature (23-26) (Table 2.), for the reaction of anthranilamdes and 4-Chlorobenzaldehyde to afford 3a (Sheme 1). As shown in Table 2, Montmorilonite KSF can act as an effective catalyst with respect to reaction times and yields of the obtained products. Thus, the present protocol with this catalyst is an alternate route for production of 2 , 3-dihydro-2-phenylquinazolin quinazolin-4(1H)-ones. All the clay catalysts tried show good catalytic activity for the reaction discussed above but some unidentified by products were observed along with the required product except when Mont. KSF was used. Furthermore it can be reused several times without any appreciable loss in activity, which clearly proves the recyclability and reusability of the catalyst (Table 2 entry 4).

${ }^{\mathrm{C}}$ Catalyst was reused for additional six runs and figures within parentheses indicate the corresponding yield for each run.

On the basis of our previous optimized conditions we started our investigations with reaction the Clay (Montmorilonite KSF) mediated catalyzed reaction of 2-aminobenzamide with various aldehydes in good to excellent yield as shown in Table 3. The reaction was compatible with variety of electron donating groups such as $\mathrm{F}, \mathrm{Cl}, \mathrm{Br}, \mathrm{OH}, \mathrm{OMe}$ and electron withdrawing groups such as $\mathrm{NO} 2$ without much affect on the product yield. Heteroarylaldehyde $(2 \mathrm{~m})$ could afford the corresponding products $(3 \mathrm{~m})$ with high yield as well (Table 3 , entry 13$)$. The use Vanillin (2n) also afforded the desired product in good yield (Table 3 , entry 14). The results acquired from the cyclisation reactions demonstrate that the method can be in general applicable for the preparation of the corresponding dihydroquinazolinones. All the products formed are well characterized by NMR and HRMS study. 


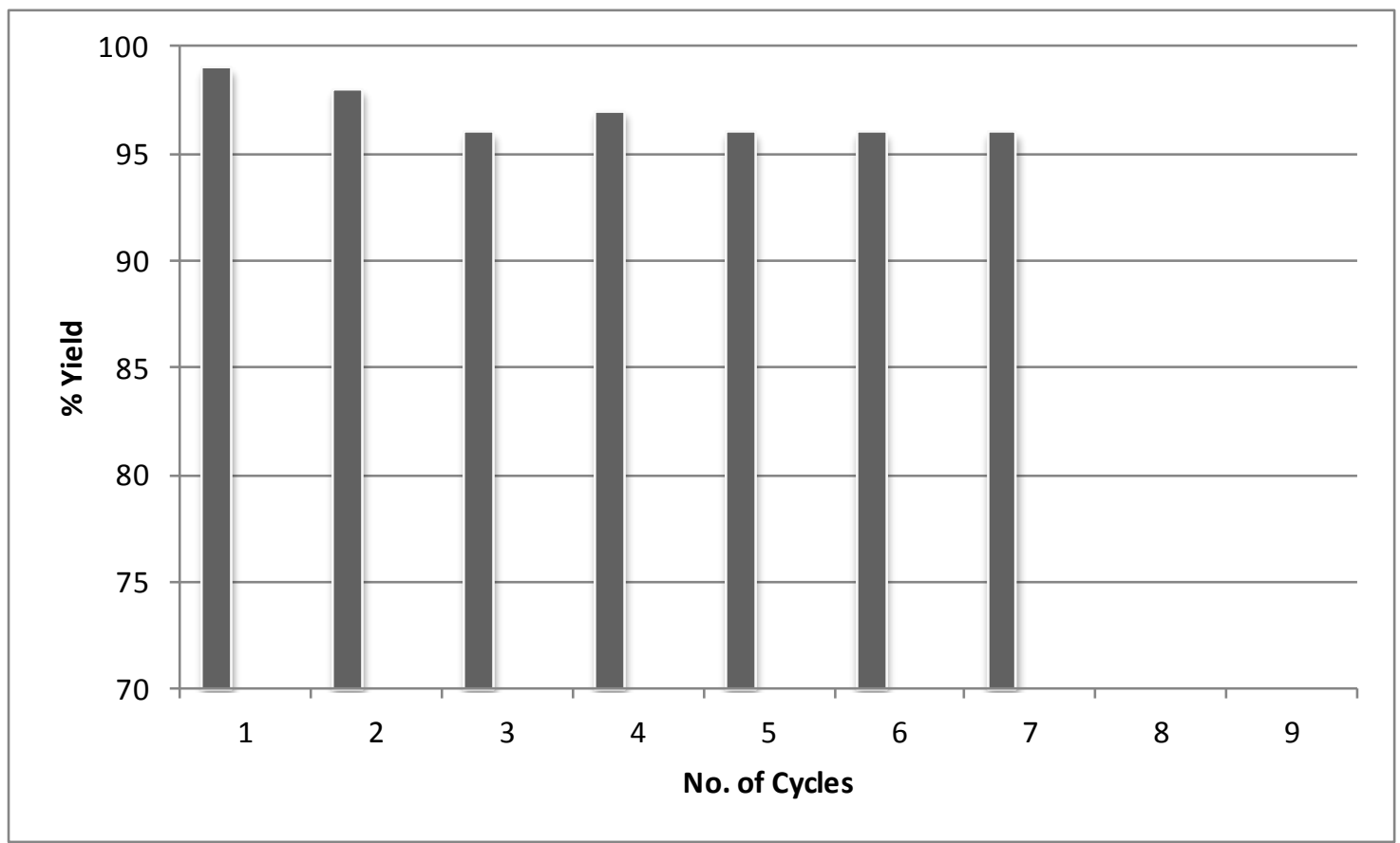

Figure 1. Recovery cycles of the catalyst

Table 2. Comparison of efficiency of various catalysts in the reaction of anthranilamdes and benzaldehyde in various reaction conditions ${ }^{\text {a }}$

\begin{tabular}{|c|c|c|c|c|}
\hline Entry & Catalyst & Conditions & Time & Yield $^{\mathrm{b}}(\%)$ \\
\hline 1 & Cellulose- $\mathrm{SO}_{3} \mathrm{H}$ & Acetonitrile, $\mathrm{RT}$ & $50 \mathrm{~min}$ & $92(23)$ \\
\hline 2 & $\left.\mathrm{KAl}_{\left(\mathrm{SO}_{4}\right)}\right)_{2} .12 \mathrm{H}_{2} \mathrm{O}$ & Ethanol, Rreflux & $4 \mathrm{~h}$ & $88(24)$ \\
\hline 3 & Silica sulfuric acid & Water, Reflux & $4 \mathrm{~h}$ & $86(25)$ \\
\hline 4 & Acetic acid & Reflux & $2.5 \mathrm{~h}$ & $79(26)$ \\
\hline 5 & Amberlyst 120 & Acetonitrile, RT & $160 \mathrm{~min}$ & 80 \\
\hline 6 & KSF & Acetonitrile, RT & $20 \mathrm{~min}$ & $99(99,98,98,97,96,97)^{\mathrm{c}}$ \\
\hline 7 & K 10 & Acetonitrile, RT & $35 \mathrm{~min}$ & 95 \\
\hline 8 & KAOLIN & Acetonitrile, RT & $30 \mathrm{~min}$ & 95 \\
\hline
\end{tabular}

${ }^{\mathrm{a}}$ Reaction conditions: all the reactions were carri ed out using 2-aminobenzamide $1 \mathrm{a}(1.0 \mathrm{mmol})$, aldehyde $2 \mathrm{a}(1.0 \mathrm{mmol})$ and Catalyst $(10 \%$, w/w) at room temperature.

${ }^{\mathrm{b}}$ Isolated yield

Table 3. KSF mediated synthesis of 2-subst it ut ed 2, 3-dihydroquinazolin-4(1 $\mathrm{H})$-ones ${ }^{\text {a }}$

\begin{tabular}{|l|c|c|c|c|}
\hline Entry & Aldehyde (2) & Time (min) $_{\text {Yield }}^{\mathrm{b}}(\%)$ \\
\hline & &
\end{tabular}




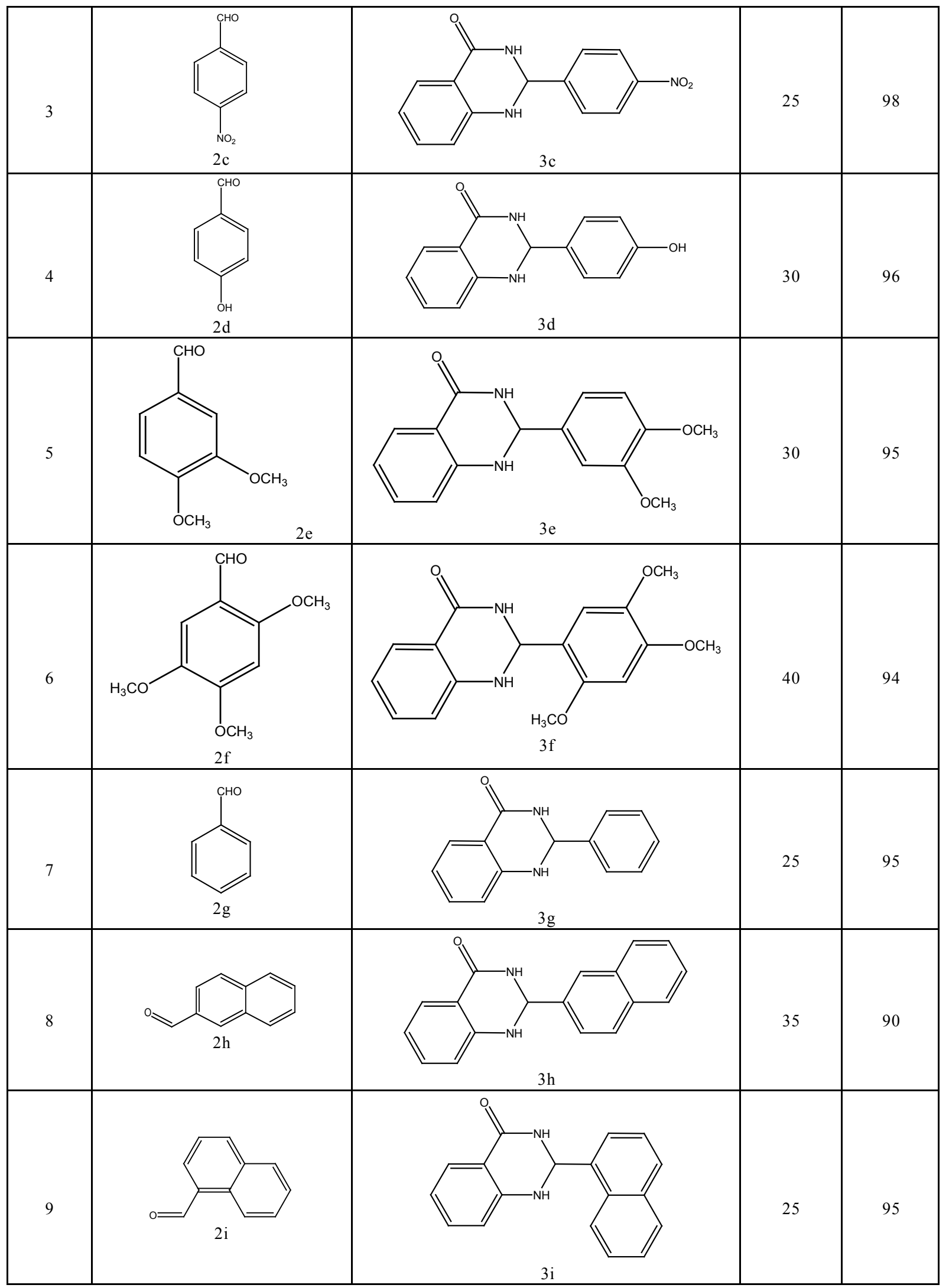


Bashir A. Dar et al.: An Easy and Efficient Protocol for the Synthesis of 2,3-Dihy droquinazo

linones Using a Low Cost and Reusable Heterogeneous Catalyst

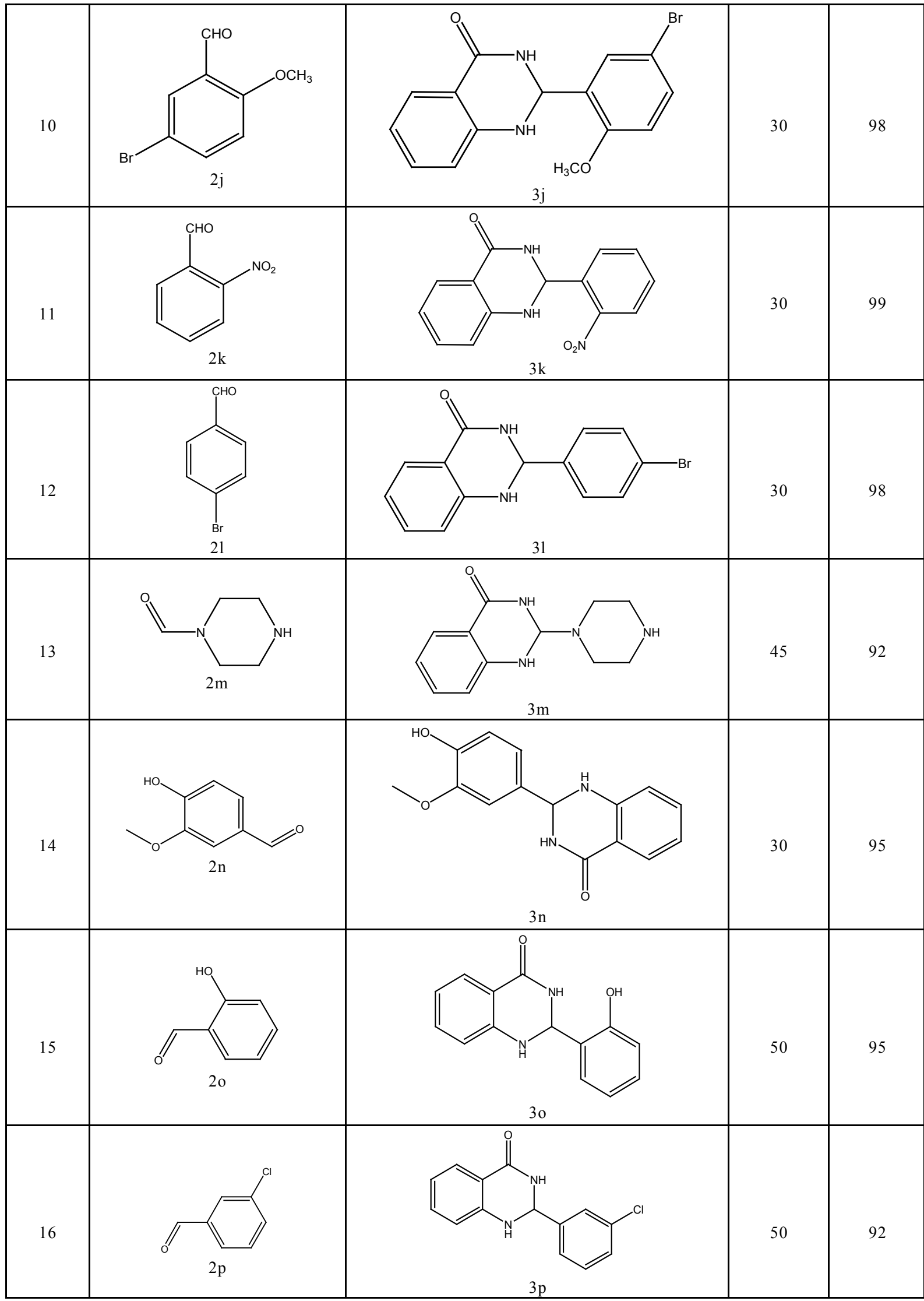

${ }^{\mathrm{a}}$ Reaction conditions: all the reactions were carried out using 2 -aminobenzamide $1 \mathrm{a}(1.0 \mathrm{mmol})$, an appropriate aldehyde $2 \mathrm{a}(1.0 \mathrm{mmol})$ and $\mathrm{KSF}(10 \%$, w/w) in $\mathrm{CH}_{3} \mathrm{CN}$ at room temperature

${ }^{b}$ Isolated yield. 


\section{Conclusions}

In conclusion, we developed a simple and environmentally friendly clay catalysed synthes is of a novel class of quinazolinones. This method allows the use of the ine xpensive, easy to prepare, efficient, easy to separate from reaction mixture and reusable clay as the catalysts and offers good results for most 2, 3-dihydroquinazolin-4(1 H)-ones. Starting materials are inexpensive and commercially available. By the reaction of a range of anthranilamides and substituted benzaldehyde, novel libraries of 2, 3-dihydroquinazo lin-4( $1 \mathrm{H})$-ones could be obtained, which would make this method a suitable candidate for combinatorial and parallel synthes is in drug discovery.

\section{ACKNOWLEDGEMENTS}

Authors are grateful to the authorities of $\mathrm{M} / \mathrm{S}$ Indian Institute of Integrated Medicine (IIIM), canal road, Jammu for providing necessary facilities to carry out the research work.

\section{REFERENCES}

[1] (a) M.J. Climent, A. Corma, and S. Iborra RSC Adv. 2,16-58(2012); (b) K. Wilson, and J.H. Clark Pure Appl. Chem. 72, 7: 1313-1319(2000); (c)R. A. Sheldon. Chemistry \& Industry 1: 12 (1997).

[2] R.S. Varma Tetrahedron Volume 58, 1235-1255(2002).

[3] (a) M.G. Biressi, G. Cantarelli, M. Carissimi, A. Cattaneo, and F. Ravenna Farmaco. Ed. Sci. 24,199(1969);(b)E.Hamel, C.M. Lin, J. Plowman, H. Wang, and K. Leeand Paull.Biochem.Pharmacol.(1996) 51:53;(c) M. Hour, L. Huang, S. Kuo, Y. Xia, K. Bastow, Y. Nakanishi, E. Hamel, and K.J. Lee Med. Chem. 43, 4479(2000);(d) D.Gravier, J.P. Dupin, F. Casadebaig, G. Hou, M. Boisseau, and H. Bernard Pharmazie 47,91(1992);(e) B.R. Baker, R.E. Schaub, J.P. Joseph, F.J. McEvoy, and J.H. Williams J. Org. Chem. 18,133(1953);(f) J.F. Wolf, T.L. Rathman, M.C. Sleevi, J.A. Campbell, and T.D. Greenwood, J. Med. Chem. 33,161(1990);(g) H.L. Yale, and M.J. Kalkstein Med. Chem. 10,334(1967);(h) G.L. Neil, L.H. Li, H.H. Buskirk, and T.E.Moxlcy Cancer Chemother. 56,163(1972); (i) G. Bonola, Da Re P, M.J. Magistretti ， E. Massarani, I. Setnikar J. Med. Chem. 11, 1136(1968); (j) J.W. Bolger US patent application US3257397A, Jun 21, 1966 ;(1966) Chem. Abstr. 66: 8933b; (k) Boehringer Sohn, C. H. French Patent M 2588, 1964; (1964)Chem. Abstr., 61:16075h;(1) R.J. Alaimo, and H.E. Russel J. Med. Chem. 15, 335(1972);(m) E. Cohen, B. Klarberg, and J.R.Vaughan J. Am. Chem. Soc. 81,5508(1959);(n) K. Okumura, T. Oine, Y. Yamada, G. Hay ashi, and M. Nakama, J. Med. Chem. 11,348(1968); (o) Instituto De Angeli S. P. A. French Patent M 1893, 1964; (1964) Chem. Abstr. 60: 3956 ;(p) I. Levin, P.S. Chan, T. Bailey, A.S. Katocs, and A.M. Venkatesan Bioorg. Med. Chem. Lett. 4, 1141(1994); (q) G.M. Chinigo, M. Paige, S. Grindrod, E. Ha mel, S. Dakshanamurthy, M. Chruszcz, W. Minor, and M.L. Brown J. Med. Chem. 51, 4620(2008).

[4] M.J. Hour, L.J. Huang, S.C. Kuo, Y. Xia, K. Bastow, Y.
Nakanishi, E. Hamel, and K.H. Lee J. Med. Chem. 43, 4479(2000).

[5] V.K. Pandey, S. Tusi, Z. Tusi, R. Raghubir, M. Dixit, and M.N. Joshi Indian J. Chem. 43,180-184(2004).

[6] (a) J.M. Khurana, and G.J. Kukreja Heterocycl Chem 40,677(2003);(b) W. Su, and B. Yang Aust J Chem 55,695(2002);(c) D. R. L. Shi, J. Wang, Q. Zhuang, X. Wang, and H. Hu Tetrahedron Lett 44,3199(2003); (d) M. Dabiri, P. Salehi, S. Otokesh, M. Baghbanzadeh, G. Kozehgarya, and A.A. Mohammadi Tetrahedron Lett 46,6123(2005);(e) P. Salehi, M. Dabiri, M. Baghbanzadeh, and M. Bahramnejad Synth Commun 36,2287(2006).

[7] (a) M. Sharma, S. Pandey, K. Chauhan, D. Sharma, B. Kumar, and P.M.S. Chauhan J. Org. Chem. 77, 929-937(2012); (b) M.J. Hour, L.J. Huang, S.C. Kuo, Y. Xia, K. Bastow, Y. Nakanishi, E. Hamel, and K.H. Lee J. Med. Chem. 43,4479(2000).

[8] A. Davoodnia, S. Allameh, A.R. Fakhari, and N. Tavakoli-Hoseini Chin ese Chem. Lett. 21, 550 (2010).

[9] Z. Jianguang, and F. Jie J. Org. Chem. dx.doi.org/10.1021/jo201054k(2011).

[10] J.X. Chen, W.K.Su, H.Y. Wu, and M.C. Liu, C. Jin Green Chem. 9,972(2007).

[11] L.Y. Zeng, and C. Cai J. Heterocycl. Chem. 47, 1035(2010).

[12] A. Shaabani, A. Maleki, and H. Mofakham Synth. Commun. 38, 3751(2008).

[13] N.B. Darvatkar, S.V. Bhilare, A.R. Deorukhkar, D.G. Raut, and M.M. Salunkhe Green Chem. Lett. Rev. 3, 301(2010).

[14] J. Chen, D. Wu, F. He, M. Liu, H. Wu, J. Ding, and W. Su, Tetrahedron Lett. 49, 3814(2008).

[15] M. Rueping, A.P. Antonchick, E. Sugiono, and K. Grenader Angew. Chem. Int. Ed. 48, 908 (2009).

[16] D.Q. Shi, L.C. Rong, J.X. Wang, Q.Y. Zhuang, X.S. Wang, and H.W. Hu Tetrahedron Lett. 44, 3199(2003).

[17] X. Cheng, S.K. Vellalath, R. Goddard, and List B. J. Am. Chem. Soc. 130, 5786(2008).

[18] A. Ghorbani-Choghamarani, and Taghipour T. Lett. Org. Chem. 8,470(2011).

[19] R.J. Abdel-Jalil, W. Voelter, and M. Saeed Tetrahedron Lett. 45, 3475(2004).

[20] (a) D.Q. Shi, L.C. Rong, J.X. Wang, X. S. Wang, S.J. Tu, and H.W. Hu Chem. J. Chin.Univ. 25, 2051(1968);(b) D.Q. Shi, J.X.Wang, L.C. Rong, Q.Y. Zhuang, S.J. Tu, and H.W. Hu J. Chem. Res., Synop. 671 (2003);(c) D.Q. Shi, L.C. Rong, J.X. Wang, Q.Y. Zhuang, X.S. Wang, and H.W. Hu Tetrahedron Lett. 44,3199(2003);(d) D.Q. Shi, C.L. Shi, J.X. Wang, L.C. Rong, Q.Y. Zhuang, and X.S. Wang J. Heterocy cl.Chem., 40, 173(2005).

[21] (a) W.K.Su, and B.B. Yang Aust. J. Chem. 55,695(2002); (b) W.K. Su, and B.B. Yang J. Chem. Res., Synop., 604(2002).

[22] (a) S.H. Lee, D.R. Park, H. Kim, J. Lee, J. C. Jung, S.Y. Woo, W.S. Song, M.S. Kwon, and I.K. Song Catal. Commun. 9, 1920(2008); (b) S. Park, K.M. C ho, M.H. Youn, J.G. Seo, S.H. Baeck, T.J. Kim, Y.M. Chung, S.H. Oh, and I.K. Song 
Catal. Lett. 122,349(2008). (c) I.K. Song, and W.Y. Lee Appl. Catal. A: Gen. 256, 77(2003).

[23] R.B.V. Subba, A. Venkateswarlu, C. Madan, and A. Venu Tetrahedron Lett.52, 1891-1894(2011).

[24] M. Dabiri, P. Salehi, S. Otokesh, M. Baghbanzadeh, G. Kozehgary, and A.A. Mohammadi Tetrahedron Letters $46,6123-6126(2005)$.
[25] M. Dabiri, P. Salehi, M. Baghbanzadeh, M.A. Zolfigol, M. Agheb, S. Heydari Catalysis Communications 9,785-788(2008).

[26] Z.K. Jaberi, R. Arjmandi Monatsh Chem 142,631-635(2011). 